\title{
A STUDY ON THE LIVELIHOOD SECURITY OF MIGRANT CHILDREN YADGIR DISTRICT, KARNATAKA STATE
}

\author{
Anandamaya Dasa \\ PhD Research Scholar, \\ Centre for Rural Development, Annamalai University, Annamalai Nagar-608002. \\ Email: anandanayadasa@gmail.com \\ Dr. P. Murugesan \\ Assistant Professor, \\ Centre for Rural Development, Annamalai University, Annamalai Nagar-608002. \\ Email: murugesancrd@gmail.com
}

\begin{abstract}
Migration shapes children and the world. It is accomplished by boosting individuals who may be more acceptant of transformation and variation and who are less observant and much more exposed and recognizing of the others, and those who have the most hurdles to overcome, like learning a foreign language, adapting to changing culture, and establishing more global connections. Based upon the origin and the social assistance provided by a host nation, children from migrant families had diverse experiences in life and possibilities. The academic achievement of migrant children and their psychological condition, social inclusion, and family responsibilities are all boosted by parental participation and action. Furthermore, it is essential for the migrant children parents should motivate their children to accept the current culture and acquire a new language, thereby maintaining their practices and culture at family. While migrant children go over the migration process, they confront various problems. The biggest issue affecting their well-being is changing surroundings, which has also become a barrier to intellectual growth and childhood happy memories. This study aims to explore the survival strategies and livelihood of migrant children. Also, it illustrates and evaluates the forces that drive children's migration and their experiences and feelings as they try to adjust to their new surroundings. This study examines migrant workers' household capital status and risk and the impact on their children. The conceptual framework is presented to understand migrant children's livelihood security.
\end{abstract}

Keywords: Capital, Household risks, Migrant Children, Migration, Socio-economic 


\section{Introduction}

Migration is becoming an essential social factor as in the modern world of the twenty-first century, impacting individuals and families of all ages. The exact number of migrant children seems to be unspecified. However, some commentators argue that "in some countries, the percentage of young people migrating can be as high as 50\%". According to the World Bank study, 330,000 children aged 6 to 17 (9.5 percent) resided away from their parents (Kielland \& Sanogo, 2002). 160,000 of these had migrated in search of work. Several child migrants pass international boundaries, whereas others migrate inside their home countries. Some might be fleeing via oppressive governments, while an insurgent guerrilla group is recruiting others. Others have been abused and are victims of human trafficking for sexual and human labor oppression. Some migrate to seek family reunification and pursue social desires that include the prospect of such a brighter future. It seems numerous young people migrate voluntarily, using it as a chance to improve their economic and social standing while also simplifying their adulthood transition process (Punch, 2007).

As a result, child migrants typically take an active part in evaluating their condition, making important decisions regarding their life paths, and negotiating the issues and opportunities that come with displacement. Even though they perceive migration as a consequence of their unique factors, it is socially a produced thing. This study examines the socio-economic conditions and security of migrant children (Ensor \& Goździak, 2010).

\section{Objectives}

The current study's objectives are listed below.

- To investigate the socio-economic conditions of migrant workers' children as introduced by Jnanadeep Balavikas Kendra.

- To examine the work opportunities, revenues, and spending habits of migrant households reviewed in this study.

- To investigate the causal factors for the migration workers chosen for this study.

- To explore the household characteristics of migrant workers;

- To assess the migrant workers' household capital status, household risk, and influence on children.

- To study the nature of security services provided by Jnanadeep Balavikas Kendra towards the migrant worker's children.

\section{Hypothesis}

Apart from capital aspects and household consequences, household attributes impact livelihood security on migrant households in their home countries.

1. The household feature aspects (total household members, household members' average age, total dependent household members, total migrants, year of migration, reason of migration, methods of migration, and frequency of remittance received.

2. Household capital aspects; economic, human, social, natural, and physical capital

3. Household risks and Household risk factor) 


\section{Literature Review}

A study on immigrant children's cognitive and emotional well-being was conducted. Barriers to access include a loss of vital workers and professionals, the necessity for a long journey, and interaction between the patient and caretaker (Perreira \& Ornelas, 2011). Dietary nutrition and diversity of children and household food insecurity are studied by Chandrasekhar et al. (2017). International remittances undoubtedly have a household food security impact. The child migration patterns, including child migrant labor in Indian cities, are investigated. The difficulties in measuring the actual child migrant's number make it hard to evaluate and analyze the effects of child migration upon children's education, well-being, death, and health, on a worldwide scale (N. R. Prabhakara, 1984). Children's labor and autonomous child migration were investigated by Edmonds and Shrestha (2009). Children of migrating parents can gain from security and contributions, yet their learning, including well-being, are often harmed (UNESCO (2019). Children's migration has traditionally been thought to be the outcome of the parents' choice to relocate. This assumption is founded on the normative concept that children are 'dependent,' 'nonproductive' family members because parents provide their necessities. Internal migration in India was studied. The factors for child migration were examined between Census 2001, with Census 2011, and NSSO-64 ${ }^{\text {th }}$ Round. As previously stated, children are defined as individuals aged 0 to 19 years old in Census 2001 and Census 2011, and migration causes are determined accordingly (Bhagat, 2010).

Research on migration, insecurity, and instability in growing manufacturing labor markets was published. After monitoring for chosen background factors like gender, residence, social position, family's level of education, and wealth status, a connection among migration status as well as four child stage performance outcomes, that are characterized as access to better immunization (Measles, Polio, DPT, and BCG), stunted growth, malnutrition, and severe diarrhea, was investigated using four binary logistic regression analyses. In comparison to nonmigrant children, migrant children tend to receive complete vaccination. However, this difference is not statistically significant (Vijay, 2005).

\section{Research Methodology}

This study provides the conceptual framework to address the various security factors of migrant children. Below are the details of the seven livelihood security of migrant children. And these are the basic sustainable security needs for migrant children.

\section{1) Economic security}

In the context of family instability, child migration could be considered a cause and effect. Whenever a child goes to work, it is believed that the household becomes shattered since the family no longer cares for their children. The children also lack parental supervision, care, and monetary help. Children do various kinds of work, and they get wages for their livelihood. The salaries are economically the basic security for them (Whitehead et al., 2005). 


\section{2) Nutritional security}

The majority of children who migrate need not earn enough money to support themselves. Consequently, young children lack all of life's fundamental essentials as in the city. The food children consume is nutritionally deficient and inexpensive. According to the findings, just a small percentage of working children could meet their regular food requirements. The majority of the time, such children's food intake has been limited to no more than two times per day. So their body gets tired, and they suffer a lot. Hence, nutritional security is very much needed for their survival (Getnet Altasseb, 2011).

\section{3) Educational security}

Children's academic achievement, social inclusion, and psychological well-being are all affected by their migratory situation. As per research, migrant children have a wide range of educational demands, and parental participation impacts academic progress and language competency. Migrant children originate from a range of backgrounds that may provide educational obstacles. Education becomes likely vital for their security requirements as it opens up additional job opportunities if they migrate to specific other locations (Carolina Acosta Gomez, 2015).

\section{4) Community participation}

The native language and the different languages both play a significant part in a children's adjustment toward a new nation. There is discussion in how children define themself within such a community and how they absorb the process of migratory. Family is significant as it affects children's emotional well-being and influences their future outcomes. Migrant children's development of self-confidence and belongingness is, however, influenced by social inclusion, community, and school integration (Suárez-Orozco, 2001).

\section{5) Habitat security (shelter environment)}

Food, shelter, clothing, and water are the necessities of migrant children in this context. Children often lack an essential for growth and survival because of the substantial nature of work: education, health care, clothing, parental care, shelter, and food. Proper shelter at their place is basic security for them. They cannot manage within the living environment without shelter (Getnet Altasseb, 2011).

\section{6) Food security}

When children see no other feasible options for escaping hunger different from migrating, the link between migration and food security might be direct. Households can exploit indirect links among migration, agriculture, and food security to deal with food insecurity and income insecurity risks. Proper intake of foods leads them to work efficiently in their working environment ("The Linkages Between Migration, Agriculture, Food Security, And Rural Development," 2019).

\section{7) Health security}

Several factors influence how children integrate the process of migration. For example, before the migration, intrinsic 29 characteristics like personal characteristics and physical 
and psychological health. Social networks become extremely vital once people have established themselves in new environments. None of it is more significant for a child's mental health than keeping relatives and friends around and offering advice and help in various situations. Furthermore, children's relationships with relatives and friends assist in their development of self-esteem and then belongingness (Suárez-Orozco \& Suárez-Orozco, 2001).

\section{The socio-economic conditions of migrant workers' children}

Individuals must build a connection between their new and old surroundings to migrate. Individuals must form new social relationships, learn social norms, and occasionally learn a foreign skill while adjusting to a unique setting. Other factors that influence migrant families' adaptation, particularly children's adaptation, seem to be the parents' socio-economic and educational backgrounds. They have a significant effect in selecting whichever area the family would relocate to. And therefore schools the children would join. For children and families, the adapting migration process requires a while, for children and families (Suárez-Orozco \& Suárez-Orozco, 2001).

\section{Household Characteristics}

Migration was frequently a dynamic state, including a range of transfers among homes of children in various locations. Economically challenged households employ migration as a coping mechanism to minimize their risks and susceptibility by expanding their livelihood possibilities. As in developing countries, most households rely upon migrant remittances to earn a living (Francis 2000). From such a young age, children consistently contribute to the economic survival of the households in a range of methods. As a result, children and youth migration is another method in which they contribute meaningfully with their own and the households' livelihoods. It was not typical in the minor culture, and labor would not be a significant part of how children are socialized. Yet, because more children live as in most nations, child migration seems to be a big issue that affects numerous rural lives, even though good figures remain hard to come across. Moreover, because employment was essential to several significant country children's lives (Punch 2003), youngsters seeking migrant labor possibilities are probably culturally objectionable and viewed as improper by children and their families. Table 1 provides the analysis of Household Characteristics and migrant factor with livelihood capital factor. And table provides the direct and indirect factors influencing on livelihood security of ISAN migrant households. 
Table 1 Household Characteristics and migrant factor with livelihood capital factor (Ayuwat \& Meekaew, 2020)

\begin{tabular}{|l|c|c|c|}
\hline \multicolumn{1}{|c|}{ Variables } & \multicolumn{3}{c|}{ Livelihood Security } \\
\cline { 2 - 4 } & $\mathbf{b}$ & Beta & Sig. \\
\hline Household characteristics and migration factor & & & \\
\hline Number of household members (NUHM) & 0.030 & 0.014 & 0.791 \\
\hline Dependent household members (DEPHM) & 0.169 & 0.057 & 0.336 \\
\hline Average age of household members (AGHM) & -0.019 & -0.089 & 0.116 \\
\hline Number of migrants (NUMIG) & -0.769 & -0.111 & 0.019 \\
\hline Migrating year (MIGYR) & 0.047 & 0.062 & 0.246 \\
\hline Migrating for helping economic household status & -0.233 & -0.041 & 0.383 \\
\hline MIGRE) & & & \\
\hline Migrating to work with neighbors (MIGME) & -0.372 & -0.059 & 0.184 \\
\hline Frequency of remittance received (REMIT) & 0.704 & 0.152 & 0.001 \\
\hline Livelihood capital factor & & & \\
\hline Lands (LAND) & 0.019 & 0.046 & 0.533 \\
\hline Annual household income (INCM) & 3.593 & -0.116 & 0.146 \\
\hline Agriculture-based income (AGINC) & -5.577 & 0.075 & 0.319 \\
\hline Non-agriculture income (NOAGINC) & -1.448 & -0.031 & 0.657 \\
\hline Savings (SAVI) & 7.780 & 0.010 & 0.844 \\
\hline Debts (DEBT) & -2.152 & -0.070 & 0.154 \\
\hline Agriculture equipment (AGEQ) & 1.324 & 0.083 & 0.078 \\
\hline Household assets (ASSVL) & 5.240 & 0.062 & 0.237 \\
\hline Human capital (HUCAP) & 0.126 & 0.305 & 0.000 \\
\hline Social capital (SOCAP) & 0.050 & 0.177 & 0.001 \\
\hline Physical capital (PHCAP) & 0.125 & 0.167 & 0.001 \\
\hline Natural capital (NACAP) & 0.019 & 0.034 & 0.001 \\
\hline Household risk factor (RISK) (Intervening variable) & $-\mathbf{0 . 0 4 2}$ & $-\mathbf{0 . 1 3 5}$ & $\mathbf{0 . 0 0 4}$ \\
\hline & & & \\
\hline
\end{tabular}

Table 2 Direct and indirect factors influencing on livelihood security of ISAN migrant households (Ayuwat \& Meekaew, 2020)

\begin{tabular}{|c|c|c|c|}
\hline Variables & $\begin{array}{l}\text { Direct } \\
\text { Effect }\end{array}$ & $\begin{array}{c}\text { Indirect } \\
\text { Effect }\end{array}$ & $\begin{array}{l}\text { Total } \\
\text { Effect }\end{array}$ \\
\hline \multicolumn{4}{|l|}{ Household characteristics and migration factor } \\
\hline Number of migrants (NUMIG) & -0.111 & & -0.111 \\
\hline Migrating year (MIGYR) & & -0.192 & -0.192 \\
\hline Migration for helping economic household (MIGRE) & & -0.109 & -0.109 \\
\hline Frequency of remittance received (REMIT) & 0.152 & & 0.152 \\
\hline \multicolumn{4}{|l|}{ Livelihood capital factor } \\
\hline Lands (LAND) & 0.046 & & 0.046 \\
\hline Annual household income (INCM) & & -0.206 & -0.206 \\
\hline Agriculture-based income (AGINC) & & 0.201 & 0.201 \\
\hline Non-agriculture income (NOAGINC) & & 0.217 & 0.217 \\
\hline Household assets (ASSVL) & & -0.118 & -0.118 \\
\hline human capital (HUCAP) & 0.305 & & 0.305 \\
\hline Social capital (SOCAP) & 0.177 & & 0.177 \\
\hline Physical capital (PHCAP) & 0.167 & & 0.167 \\
\hline Natural capital (NACAP) & 0.034 & & 0.034 \\
\hline Household risk factor (RISK) (Intervening variable) & -0.135 & & -0.135 \\
\hline
\end{tabular}

\section{Livelihood Assets:}

Assets are crucial to livelihood analysis in the livelihood approach. Such elements of a Sustainable Livelihood depend on the presence of diverse livelihood assets to accomplish livelihood strategies established through changing frameworks (private /government sector 
/NGOs) or procedures (institutions, culture, law, and policies). Such tactics were utilized to attain sustainable livelihoods (like greater well-being and decreased risk) based upon that asset's stock (Ashley \& Carney 1999).

Human capital: This is commonly stated that the poor's most valuable asset would be their work. Human capital is defined as the household's labor force, including health, skills, and education. In urban labor markets, human capital lack in terms of education and skills seems to have a more direct impact than in rural labor markets (Ellis 2000).

Social capital: The norms, rules, responsibilities, cooperation, and confidence embedded in human relationships, social systems, and current societal, institutional structures that allow individuals to achieve their personal and societal goals, are referred to as social capital (Rakodi, 2006).

Financial capital: Financial capital is a term that refers to cash holdings that could be used to buy either manufacturing or used items. Wealth and access to loans as in the form of loans are the most likely options. Money savings and loans aren't immediately productive types of capital; they depend on their position in a household's asset portfolio to their ability to be converted into other kinds of capital or consumed (Ellis 2000). Poor urban households' capacity to provide and obtain credit is limited, leading to a shortage of banking and finance based on individual needs (Rakodi, 2006).

Natural capital: Natural capital depends on the natural asset base (soil, trees, and water) that generates items humans need to survive. These are sometimes known as environmental assets, and they are all considered part of 'nature.' A difference among non - renewable and renewable natural resources was established under natural capital (Carney 1998).

Physical capital: Physical capital refers to capital that is formed as a result of economic production activities. Physical assets include structures, irrigation systems, highways, equipment, and technology, among other things. Physical capital seems to be a production good, as opposed to a commodity, in economic terms (Ellis 2000).

\section{Household risks and Household risk factors}

One core tenet of such a theoretical study would be that families develop economic strategies that aim not just to optimize household income (like in the Todaro framework) but to avoid risk. Poor households experience severe risks towards well-being since economic circumstances in emerging regions are somewhat risky. Families in rural and urban service sectors typically exist close to the sustainable level. Aside from the obvious risks of food insecurity, poor soil fertility, and natural calamities, the economic and social conversions during industrialization and transformation build a robust, unpredictable, and uncertain economic environment in both towns and cities. As in the lack of many other choices for mitigating risks, family members' migration towards diversified labor markets 
provides to decreases the danger towards the household income (Srinivasan \& Bhagwati, 1974).

The growth and development of migrant channels seem to allow migration overall, and migration flows in specific, appealing like a strategic plan (Stark et al., 1986). Once migrant channels are well-developed, a target task is easily accessible to most community members, creating it such a dependable and risk-free economic asset (Massey \& España, 1987). Thereby, a self-feeding expansion of channels happens as a result of gradual reducing costs as well happens as a result of gradual risk mitigation. Each fresh migrant broadens the system and helps reduce the risk of movement with all those to whom he has been connected, finally making household labor allotments practically risk-free and cost-free.

As a result, a lengthy problem in macroeconomics was the degree to which employment growth encourages the flow of migrants (Blanco, 1964) and migration boosts employment levels $(\mathrm{H}$. Borts \& L. Stein, 1964). Capital seems to be a resolved factor of economic growth, and also its owners should pay the costs, including its unemployment. Labor would be a variable factor in economic development that could be published via capital when no longer required. Also, its owners, notable workers, must pay for its unemployment.

\section{Conclusion}

The reduction of migration from the rural towards urban regions is becoming critical. Rural infrastructure development, as well as more significant job opportunities, may decrease migration and also migrant population from the urban areas. Migration is an option, not a requirement. The government addresses the structural causes of high population activities and develops rules that enable communities to live peacefully and in instability within their native countries. The government must invest heavily in rural growth to supply food security, wellequipped improved sanitation, and necessities like safe drinking water and electricity to the local population. So the need for migration is lowered, and also, the migrant worker's families, who are most vulnerable, can reside and develop in their home country. As a result, this study provides the livelihood security of migrant children.

\section{References}

1) Kielland, A., \& Sanogo, I. (2002). Burkina Faso: Child Labor Migration From Rural Areas The Magnitude And The Determinants. Washington, DC: The World Bank Terre des Hommes.

2) Punch, S. (2007). Negotiating Migrant Identities: Young People in Bolivia and Argentina. Children's Geographies, 5(1-2),

95-112. https://doi.org/10.1080/14733280601108213

3) Ensor, M., \& Goździak, E. (2010). Introduction: Migrant Children at the Crossroads. Children And Migration, 1-12. https://doi.org/10.1057/9780230297098_1.

4) Perreira, K. M., \& Ornelas, I. J. (2011). The physical and psychological well-being of immigrant children. The Future of Children, 195-218. 
5) Chandrasekhar, S., Aguayo, V. M., Krishna, V., \& Nair, R. (2017). Household food insecurity and children's dietary diversity and nutrition in India. Evidence from the comprehensive nutrition survey in Maharashtra. Maternal \& child nutrition, 13, e12447.

6) Prabhakara, N. R. (1984). Patterns of child migration and child migrant labour in the cities of India. Janasamkhya, 2(1), 19-28.

7) Edmonds, E., \& Shrestha, M. (2009). Children's work and independent child migration: a critical review.

8) Bhagat R.B. (2010). Internal migration in India: Are the underprivileged migrating more? Asia Pacific Population Journal, 25 (1), 31-49.

9) Vijay, G. (2005). Migration, Vulnerability and Insecurity in New Industrial Labour Markets. Economic and Political Weekly, 40(23).

10) Whitehead, A., M. Hashim, I., \& Iversen, V. (2005). Child Migration, Child Agency And Intergenerational Relations In Africa And South Asia. Oslo: Children and Youth in Emerging and Transforming Societies Childhoods.

11) Getnet Altasseb, H. (2011). Livelihoods And Survival Strategies Among The Migrant ShoeShinning Children: A Case Study At Arada Sub-City, Addis Ababa. Institute of Development Studies. Retrieved from http://africanphilanthropy.issuelab.org/resources/20068/20068.pdf

12) Carolina Acosta Gomez, L. (2015). Migration and its impact on children's lives: a literature review. School of Social Sciences University of Iceland. Retrieved from https://skemman.is/bitstream/1946/21378/1/loka\%20loka.pdf

13) Suárez-Orozco, M. (2001). Globalization, Immigration, and Education: The Research Agenda. Harvard Educational Review, 71(3), 345-366. https://doi.org/10.17763/haer.71.3.7521rl25282t3637

14) The Linkages Between Migration, Agriculture, Food Security And Rural Development. Fao.org. (2019). Retrieved 7 December 2021, from https://www.fao.org/3/ca0922en/ca0922en.pdf.

15) Suárez-Orozco, C., \& Suárez-Orozco, M. (2001). Children of immigration. Harvard University Press.

16) Francis, E. (2000). Making a living. Routledge.

17) Punch, S. (2003). Childhoods in the Majority World: Miniature Adults or Tribal Children?. Sociology, 37(2), 277-295. https://doi.org/10.1177/0038038503037002004

18) Moraru, A. (2021). Lessons Learned from the European Union's Experience in Capitalizing Architectural Heritage. Oalib, 08(04), 1-9. https://doi.org/10.4236/oalib.1107372

19) Ashley, C., \& Carney, D. (1999). Sustainable Livelihoods: Lessons from early experience. DFID, London. Retrieved 7 December 2021.

20) Ellise, F. (2000) Rural Livelihoods and Diversity in Developing Countries, Oxford University Press.

21) Rakodi, C. (2006). Urban livelihoods. Earthscan.

22) Carney, D. (1998) Sustainable rural livelihoods. What contribution can we make, DFID, London.

23) Srinivasan, T., \& Bhagwati, J. (1974). "On Reanalyzing the Harris-Todaro Model: Policy Rankings in the Case of Sector-Specific Sticky Wages. American Economic Review, 64, 502- 8.

24) Stark, O., Taylor, J., \& Yitzhaki, S. (1986). Remittances and Inequality. The Economic Journal, 96(383), 722. https://doi.org/10.2307/2232987 
25)Massey, D., \& España, F. (1987). The Social Process of International Migration. Science, 237(4816), 733-738. https://doi.org/10.1126/science.237.4816.733

26) Blanco, C. (1964). Prospective Unemployment and Interstate Population Movements. The Review Of Economics And Statistics, 46(2), 221. https://doi.org/10.2307/1928188

27) H. Borts, G., \& L. Stein, J. (1964). Economic growth in a free market (p. 235). Columbia University Press.

28) Ayuwat, D., \& Meekaew, N. (2020). Livelihoods and Food Security of the Migrant Households in the rural community of the Lower- northeastern Region of Thailand. Systematic Reviews In Pharmacy, 11(6), 1311-1319. 